Article

\title{
Bioactivity of Natural and Engineered Antimicrobial Peptides from Venom of the Scorpions Urodacus yaschenkoi and $U$. manicatus
}

\author{
Karen Luna-Ramirez ${ }^{1}$, Miray Tonk ${ }^{1}$, Mohammad Rahnamaeian ${ }^{1}$ and Andreas Vilcinskas ${ }^{1,2, *}$ \\ 1 Fraunhofer Institute for Molecular Biology and Applied Ecology, \\ Winchester Strasse 2, D-35394 Giessen, Germany; karenlunarmrz@gmail.com (K.L.-R.); \\ miray.tonk@ime.fraunhofer.de (M.T.); mohammad.rahnamaeian@ime.fraunhofer.de (M.R.) \\ 2 Institute for Insect Biotechnology, Justus Liebig University of Giessen, D-35392 Giessen, Germany \\ * Correspondence: andreas.vilcinskas@agrar.uni-giessen.de
}

Academic Editor: Eivind Undheim

Received: 26 November 2016; Accepted: 29 December 2016; Published: 6 January 2017

\begin{abstract}
The spread of multidrug-resistant human pathogens has drawn attention towards antimicrobial peptides (AMPs), which are major players in the innate immune systems of many organisms, including vertebrates, invertebrates, plants and microbes. Scorpion venom is an abundant source of novel and potent AMPs. Here, we investigated natural and engineered AMPs from the scorpions Urodacus yaschenkoi and $U$. manicatus to determine their antimicrobial spectra as well as their hemolytic/cytotoxic activity. None of the AMPs were active against fungi, but many of them were active at low concentrations $(0.25-30 \mu \mathrm{M})$ against seven different bacteria. Hemolytic and cytotoxic activities were determined using pig erythrocytes and baby hamster kidney cells, respectively. The amino acid substitutions in the engineered AMPs did not inhibit cytotoxicity, but reduced hemolysis and therefore increased the therapeutic indices. The phylogenetic analysis of scorpion AMPs revealed they are closely related and the GXK motif is highly conserved. The engineered scorpion AMPs offer a promising alternative for the treatment of multidrug-resistant bacterial infections and could be modified further to reduce their hemolytic/cytotoxic activity.
\end{abstract}

Keywords: antimicrobial peptides; venom; hemolysis; therapeutic index; scorpions

\section{Introduction}

The emergence and spread of bacteria that are resistant to many routinely-used antibiotics has driven research into the development of new classes of antimicrobial agents with high antibacterial efficacy and new modes of action. Naturally occurring antimicrobial peptides (AMPs) are essential components of the innate immune system in many different organisms, and they are characterized by diverse targets and mechanisms of action, broad-spectrum activity and only rare instances of resistance [1-4]. AMP gene families have expanded and diversified particularly among the arthropods, compensating for the lack of an adaptive immune system [5].

AMPs have been isolated and characterized from many arthropods, including insects [6,7], ticks [8,9] and scorpions [10-12]. Natural AMPs generally have short, cationic, amphipathic and $\alpha$-helical structures that interact preferentially with microbial membranes via electrostatic contacts $[13,14]$. Increasing the net positive charge and hydrophobicity enhances the antibacterial activity of AMPs due to the greater affinity for the negatively-charged bacterial membrane [15]. However, the therapeutic value of AMPs is limited by their hemolytic activity, which is particularly prevalent in the case of scorpion AMPs. The therapeutic index of AMPs can be improved by reducing their hemolytic activity, which can be achieved by engineering new versions with suitable amino acid substitutions [16]. 
Here, we describe the functional characterization of natural and engineered versions of the scorpion AMPs UyCT1, UyCT3, UyCT5, Uy17, Uy192 and Uy234 from Urodacus yaschenkoi, and Um2, Um3, Um4 and Um5 from $U$. manicatus [17-20]. The AMPs were tested for antifungal, antibacterial, hemolytic and cytotoxic activities in order to identify more potent and selective versions with a higher therapeutic index.

\section{Results}

\subsection{Peptide Engineering}

To engineer enhanced scorpion AMPs, we aimed to keep the conserved residues and retain the amphipathic properties of the engineered sequences (Table 1).

Table 1. Native and engineered scorpion AMPs used in this study. All AMPs were C-terminally amidated.

\begin{tabular}{ccccccc}
\hline AMP & Amino Acid Sequence & MW $(\mathbf{D a})$ & Length & Net Charge & GRAVY $^{+}$ & Accession No. \\
\hline UyCT1 & GFWGKLWEGVKNAI & 1603.9 & 14 & +2 & -0.050 & AGA82754 \\
UyCT3 & ILSAIWSGIKSLF & 1433.7 & 13 & +2 & 1.392 & AGA82755 \\
UyCT5 & IWSAIWSGIKGLL & 1442.7 & 13 & +2 & 1.138 & AGA82756 \\
\hline Uy17 & ILSAIWSGIKGLL & 1369.43 & 13 & +2 & 1.500 & SRP045734* $^{*}$ \\
Uy192 & FLSTIWNGIKGLL & 1459.98 & 13 & +2 & 0.969 & SRP045734 $^{*}$ \\
Uy234 & FPFLLSLIPSAISAIKRL & 1986.19 & 18 & +3 & 1.328 & SRP045734 $^{*}$ \\
\hline Um2 & ISQSDAILSAIWSGIKSLF & 2034.56 & 19 & +1 & 0.832 & JAA98072 \\
Um3 & GFWGKLWEGVKSAI & 1577.23 & 14 & +2 & 0.143 & JAA98071 \\
Um4 & FFSALLSGIKSLF & 1428.58 & 13 & +2 & 1.492 & JAA98071 \\
Um5 & IFKAIWSGIKSLF & 1508.82 & 13 & +3 & 1.077 & JAA98069 \\
\hline D1 & IFGAIWSGIKSLF & 1437.11 & 13 & +2 & 1.346 & - \\
D2 & FLSTIWNGIKSLF & 1524.00 & 13 & +2 & 0.862 & - \\
D4 & GFWGKLWKPVKKAI & 1657.87 & 14 & +5 & -0.193 & - \\
D5 & GFWGKLLEGVKKAI & 1544.52 & 14 & +3 & 0.257 & - \\
D10 & FPFLKLSLKIPKSAIKSAIKRL & 2497.71 & 22 & +7 & 0.377 & - \\
D11 & GFWGKLWEGVKNAIKKK & 1987.55 & 17 & +5 & -0.729 & - \\
\hline
\end{tabular}

${ }^{*}$ High-throughput DNA and RNA sequence read archive (SRA); the peptides were taken from the transcriptome of Urodacus yaschenkoi [17].

The aligned UyCT peptides revealed a conserved Trp residue in the middle of the sequence and the $\mathrm{G}(\mathrm{V} / \mathrm{I}) \mathrm{K}$ motif near the $\mathrm{C}$-terminus, and these elements were retained (Figure 1 ).

The mutations were made by interchanging other amino acids and inserting positively charged residues to increase the net positive charge and hence bacterial membrane affinity (Table 2).

Table 2. The engineered AMPs along with their parent sequences used in this study. The changed residues are shown in bold.

\begin{tabular}{ll}
\hline Peptide & Sequence \\
\hline UyCT3 & ILSAIWSGIKSLF \\
D1 & IFGAIWSGIKSLF \\
\hline Uy192 & FLSTIWNGIKGLL \\
D2 & FLSTIWNGIKSLF \\
\hline UyCT1 & GFWGKLWEGVKNAI \\
D4 & GFWGKLWKPVKKAI \\
D5 & GFWGKLLEGVKKAI \\
D11 & GFWGKLWEGVKNAIKKK \\
D12 & GFWKGKLWKEGVKNAIK \\
\hline Uy234 & FPFL-LSL-IP-SAI-SAIKRL \\
D10 & FPFLKLSLKIPKSAIKSAIKRL \\
\hline
\end{tabular}




\begin{tabular}{|c|c|}
\hline BmKn2 & ------FIGAIANLLSKI----F- \\
\hline Meucin-13 & ------IFGAIAGLLKNI----F- \\
\hline ctriporin & -----FLWGLIPGAISAVTSLIKK \\
\hline Uy234 & ---FPFLLSLIPSAISAIKRL--- \\
\hline TSAP-1 & ------FLSLIPSLVGGSISAFK- \\
\hline TSAP-2 & ------FLGMIPGLIGGLISAFK- \\
\hline Imcroporin & ------FFSLLPSLIGGLVSAIK- \\
\hline Mucroporin & ------LFGLIPSLIGGLVSAFK- \\
\hline $\mathrm{BmKb1}$ & -----FLFSLIPSAISGLISAFK- \\
\hline AamAP2 & -----FPFSLIPHAIGGLISAIK- \\
\hline VsCT1 & ------FLKGIIDTVSNWL----- \\
\hline VsCT2 & ------FLKGIIDTVSKLF----- \\
\hline Meucin-18 & ------FFGHLFKLATKIIPSLFQ \\
\hline $\mathrm{VmCT} 2$ & ------FLSTLWNAAKSIF----- \\
\hline VmCT1 & ------FLGALWNVAKSVF----- \\
\hline StCT1 & -----GFWGSLWEGVKSVV----- \\
\hline Uуст1 & -----GFWGKLWEGVKNAI----- \\
\hline Um3 & -----GFWGKLWEGVKSAI----- \\
\hline StCT2 & -----GFWGKLWEGVKSAI----- \\
\hline Pantinin-1 & -----GILGKLWEGFKSIV----- \\
\hline Um4 & ------FFSALLSGIKSLF----- \\
\hline Uy 192 & ------FLSTIWNGIKGLL----- \\
\hline Pantinin-3 & ------FLSTIWNGIKSLL----- \\
\hline Pantinin-2 & ------IFGAIWKGISSLL----- \\
\hline IsCT & ------ILGKIWEGIKSLF----- \\
\hline IsCT2 & ------IFGAIWNGIKSLF----- \\
\hline Um5 & ------IFKAIWSGIKSLF----- \\
\hline Hp1090 & ------IFKAIWSGIKSLF----- \\
\hline Uyст3 & ------ILSAIWSGIKSLF----- \\
\hline Um2 & ISQSDAILSAIWSGIKSLF----- \\
\hline UyCt5 & ------IWSAIWSGIKGLL----- \\
\hline Uy 17 & ------ILSAIWSGIKGLL----- \\
\hline
\end{tabular}

Figure 1. Amino acid sequence alignment of the scorpion AMPs by Clustal Omega. Accession numbers: Scorpiops tibetanus: StCT1 (PODJO3), StCT2 (PDJO4); Pandinus imperator: Pantinin 1 (AGK88380), Pantinin 2 (AGK88381), Pantinin 3 (AGK88382); Heterometrus petersii: Hp1090 (P0DJ02); Opisthacanthus madagascariensis: IsCT1 (Q8MMJ7), IsCT2 (Q8MTX2); Vaejovis mexicanus: VmCT1 precursor (AFH87944), VmCT2 precursor (AFH87945); Mesobuthus eupeus: Meucin-18 (E4VP50); Chaerilus tricostatus: Ctriporin (G1FE62); Mesobuthus martensii: BmKb1 (Q718F4), BmKn2 (Q6JQN2); Androctonus amoreuxi: AamAP2 (G8YYA6); Lychas mucronatus: Mucroporin (B9UIY3); Isometrus maculatus: Imcroporin (C7B247); Tityus serrulatus: TsAP-1 precursor (CCQ98791), TsAP-2 precursor (CCQ98792); Mesobuthus eupeus: Meucin-13 (E4VP07); Vaejovis subcristatus: VsCT1 and VsCT2 (EST database: dbEST JZ818318-JZ818449); Urodacus yaschenkoi: UyCT1 (AGA82754), UyCT3 (AGA82755), UyCT5 (AGA82756); Urodacus manicatus: Um2 (JAA98072), Um3 (JAA98071), Um4 (JAA98070), Um5 (JAA98069). 


\subsection{Antimicrobial Assays}

The antimicrobial activities of 16 scorpion-derived natural and engineered AMPs were evaluated against the Gram-positive bacteria L. monocytogenes, L. grayi, L. fleischmannii, S. aureus and M. luteus, and the Gram-negative bacteria E. coli and P. aeruginosa. M. luteus was the most susceptible species, and it was completely inhibited in the presence of $0.25 \mu \mathrm{M}$ D10 or D11 (Table 3). Most of the AMPs showed no effect against $P$. aeruginosa even at the highest concentration we tested $(250 \mu \mathrm{M})$, but UyCT1 and D11 were able to inhibit the growth of this species at $60 \mu \mathrm{M}$ and $30 \mu \mathrm{M}$, respectively. UyCT5, Uy192, Um3 and Um4 were the most broadly-active AMPs, inhibiting all the bacterial species we tested except $P$. aeruginosa. D10, D11 and Um5 displayed the lowest MIC values. Table 3 summarizes the MIC values, cytotoxicity (ECx) and hemolytic activity ( $\mathrm{HCx}$ ) of the most active AMPs.

Antifungal activity was assessed using two major phytopathogenic fungi, F. culmorum and F. graminearum. None of the tested scorpion peptides showed any effect on fungi, even at the concentration of $200 \mu \mathrm{M}$.

\subsection{Hemolytic Assays}

The hemolytic effect of the scorpion AMPs was tested by exposing pig erythrocytes to $100 \mu \mathrm{M}$ of each peptide (Table 3). The percentage of hemolysis was calculated using $10 \%$ Triton X-100 as a positive control (100\% hemolysis). Um4 and D4 were the least hemolytic peptides, causing $9 \%$ and $1.7 \%$ hemolysis at the highest tested concentration $(100 \mu \mathrm{M})$, respectively, but it was not technically possible to calculate $\mathrm{HC}_{50}$ values because the data did not fit the curve. Engineered peptides D5, D10 and D11 caused limited hemolysis ( 10\% each). The most hemolytic peptides were UyCT5 and D2, which caused $70 \%$ and $64 \%$ hemolysis, respectively. In contrast, Um4 and D4 showed less than $1 \%$ hemolytic activity. The $\mathrm{HC}_{50}$ values for the natural and engineered AMPs ranged from 20 to $142 \mu \mathrm{M}$ and 24 to $1700 \mu \mathrm{M}$, respectively.

\subsection{Cytotoxicity Assays}

The natural and engineered AMPs were mildly cytotoxic against BHK-21 cells (Table 3). Engineered peptides D2, D4, D5 and D10 were less cytotoxic than the other AMPs. D4 and D10 are engineered versions of UyCT1. The engineered peptides showed more desirable $\mathrm{EC}_{50}$ and $\mathrm{HC}_{50}$ values than the natural peptide, indicating that the rationale for the engineering strategy was correct, producing safer and more potent molecules. The least cytotoxic natural AMPs were Uy17, Uy192, Um3 and Um4.

\subsection{Phylogenetic Analysis}

A phylogenetic tree comprising all of the reported active natural scorpion AMPs and the tested herein was built using ClustalW2 Phylogeny based on the Nexus UPGMA model, revealing four major clades (Figure 2). The first clade comprised sequences similar to UyCT1, including two AMPs from Scorpiops tibetanus (StCT1 and STCT2) and Um3, which differs by only one amino acid from UyCT1. Pantinin-1 form Pandinus cavimanus is also included in this clade. The second clade contained sequences similar to UyCT3. This was more diverse, containing sequences from $U$. yaschenkoi (UyCT3, UyCT5, Uy17, Uy192), U. manicatus (Um2, Um5, Um4), Pandinus cavimanus (Pantinin-2, Pantinin-3), Heterometrus petersii (Hp1090), Opisthacanthus madagascariensis (IsCT1, IsCT2), Mesobuthus eupeus (Meucin-18) and Vaejovis mexicanus (VmCT1, VmCT2). Third clade comprised the longer AMPs (17-19 residues, whereas all the other AMPs were 13-14 residues in length). All the AMPs in this clade are secreted from scorpions representing the Buthidae family, except ctriporin which represents the Chaerilidae family and Uy234 from the Urodacidae family. The fourth clade contained AMPs 13 residues in length, including VsCT1 and VsCT2 from Vaejovis subcristatus, which showed no antibacterial activity [21]. 


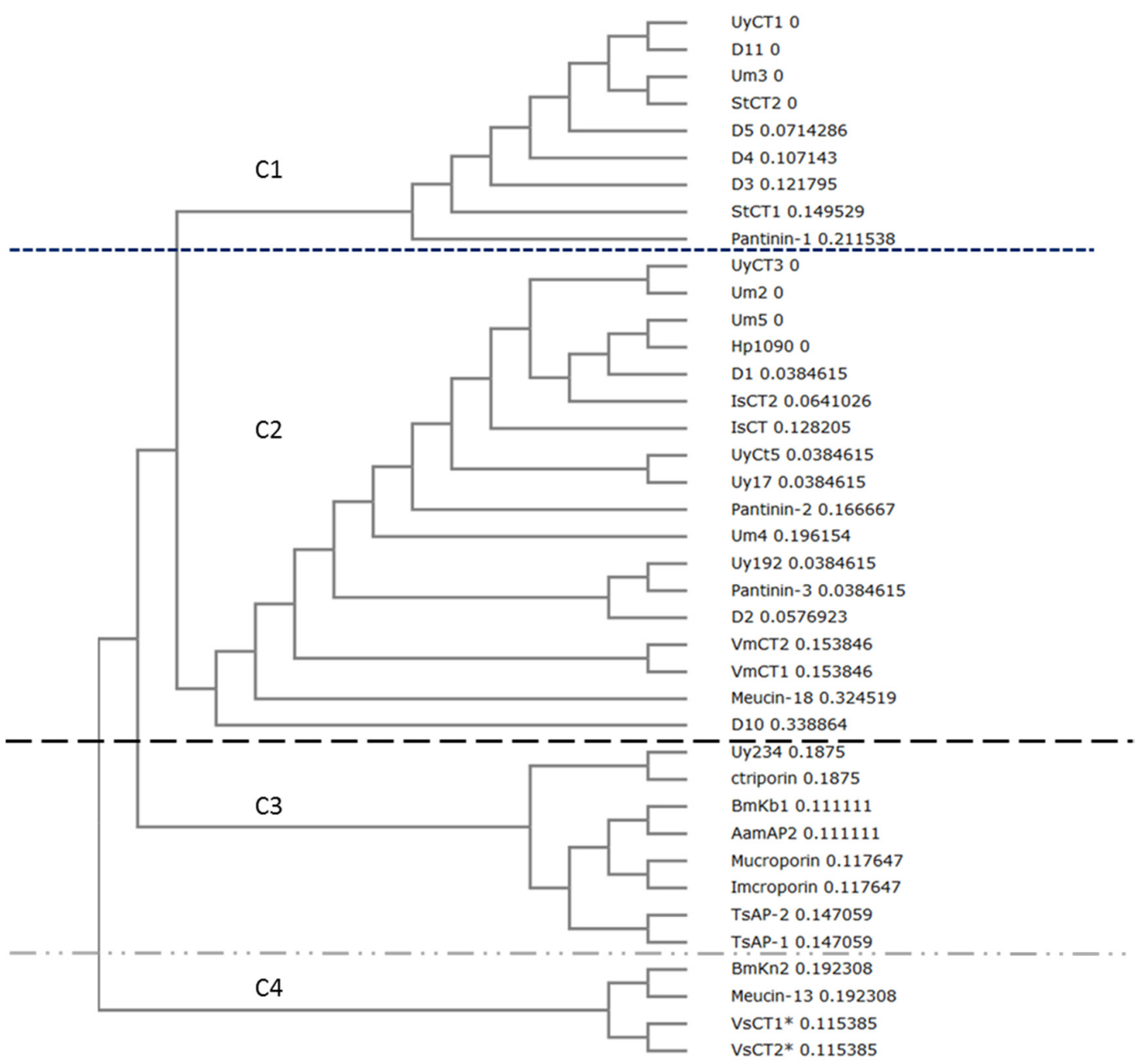

Figure 2. Phylogenetic analysis of natural and designed scorpion AMPs with ClustalW2 Phylogeny using the Nexus UPGMA model. Tree shows the cladistic relationship between AMPs. Branch length is included beside the name of the peptide. Accession numbers: Scorpiops tibetanus: StCT1 (PODJO3), StCT2 (PDJO4); Pandinus imperator: Pantinin 1 (AGK88380), Pantinin 2 (AGK88381), Pantinin 3 (AGK88382); Heterometrus petersii: Hp1090 (P0DJ02); Opisthacanthus madagascariensis: IsCT1 (Q8MMJ7), IsCT2 (Q8MTX2); Vaejovis mexicanus: VmCT1 precursor (AFH87944), VmCT2 precursor (AFH87945); Mesobuthus eupeus: Meucin-18 (E4VP50); Chaerilus tricostatus: Ctriporin (G1FE62); Mesobuthus martensii: BmKb1 (Q718F4), BmKn2 (Q6JQN2); Androctonus amoreuxi: AamAP2 (G8YYA6); Lychas mucronatus: Mucroporin (B9UIY3); Isometrus maculatus: Imcroporin (C7B247); Tityus serrulatus: TsAP-1 precursor (CCQ98791), TsAP-2 precursor (CCQ98792); Mesobuthus eupeus: Meucin-13 (E4VP07); Vaejovis subcristatus: VsCT1 and VsCT2 (EST database: dbEST JZ818318-JZ818449); Urodacus yaschenkoi: UyCT1 (AGA82754), UyCT3 (AGA82755), UyCT5 (AGA82756); Urodacus manicatus: Um2 (JAA98072), Um3 (JAA98071), Um4 (JAA98070), Um5 (JAA98069). Identity of the clade is represented by C\#, in example $\mathrm{C} 1$ = clade 1 . 
Table 3. The antimicrobial, cytotoxic and hemolytic profiles of native and engineered scorpion AMPs. MIC values were determined against seven different bacterial strains, cytotoxic values (ECx) against baby hamster kidney cells (BHK21) cells and hemolytic activity (HCx) towards pig erythrocytes. The values are the concentrations in $\mu \mathrm{M}$. Values are the average of at least three independent experiments $(n \geq 3)$.

\begin{tabular}{|c|c|c|c|c|c|c|c|c|c|c|c|c|}
\hline AMP & M. luteus & E. coli & S. aureus & L. grayi & L. fleischmannii & L. monocytogenes & $\mathrm{EC}_{10}$ & $\mathrm{EC}_{50}$ & $\mathrm{EC}_{90}$ & $\mathrm{HC}_{10}$ & $\mathrm{HC}_{50}$ & $\mathrm{HC}_{90}$ \\
\hline UyCT1 & 1 & 4 & - & 4 & 4 & 4 & 0.65 & 17.37 & 52.12 & 31.5 & 142.50 & 644.46 \\
\hline UуСТ3 & 4 & 8 & - & 8 & 4 & 4 & 0.57 & 15.37 & 46.12 & 15.78 & 58.15 & 214.22 \\
\hline UyCT5 & 4 & 15 & 8 & 8 & 8 & 4 & 0.91 & 24.55 & 73.65 & 2.39 & 20.59 & 177.49 \\
\hline Uy17 & 15 & - & 30 & - & - & 15 & 2.73 & 73.63 & 220.80 & 26.65 & 138.40 & 718.55 \\
\hline Uy192 & 15 & 15 & 15 & 15 & 4 & 8 & 1.92 & 51.95 & 155.90 & 35.85 & 155.6 & 675.22 \\
\hline Uy234 & 2 & - & - & 4 & - & 2 & 0.23 & 6.29 & 18.86 & 55.14 & 104.50 & 198.04 \\
\hline Um2 & 4 & - & - & - & - & - & 0.58 & 15.71 & 47.12 & 2.36 & 129 & 7033.22 \\
\hline Um3 & 2 & 15 & 15 & 4 & 4 & 8 & 2.359 & 63.68 & 191.1 & 70.48 & 126.2 & 246.84 \\
\hline Um4 & 8 & 8 & 15 & 15 & 4 & 8 & 3.22 & 87.01 & 261 & n.c. & n.c. $(100)$ & n.c. \\
\hline Um5 & 2 & 15 & - & 2 & 2 & 2 & 0.36 & 9.71 & 29.12 & 11.944 & 59.25 & 293.90 \\
\hline D1 & 4 & 8 & - & 8 & 4 & 4 & 0.69 & 18.58 & 55.75 & 15.50 & 48 & 148.51 \\
\hline D2 & 4 & - & 8 & - & 15 & 15 & 13.95 & 376.70 & 1130 & 2.94 & 24.48 & 200.83 \\
\hline D4 & 2 & - & - & 8 & 15 & 30 & 36.30 & 980 & 2940 & n.c. & n.c. (100) & n.c. \\
\hline D5 & 8 & 15 & - & 8 & 15 & 15 & 2.50 & 67.63 & 202.90 & 110.86 & 1636 & $24,141.72$ \\
\hline D10 & 0.25 & 8 & - & 8 & 30 & 30 & 5.24 & 141.40 & 424.30 & 149.75 & 1726 & $19,894.17$ \\
\hline D11 & 0.25 & 4 & - & 1 & 1 & 2 & 0.66 & 17.81 & 53.43 & 39.76 & 1110 & $30,984.53$ \\
\hline
\end{tabular}

EC: effective cytotoxic concentration; HC: hemolytic concentration; n.c.: not convergent; n.c. (100): not convergent at $100 \mu \mathrm{M}$. 


\section{Discussion}

Scorpion venoms contain hundreds of different compounds that target membranes, ion channels and receptors [22,23]. One class of compounds, known as "non-disulfide-bridged peptides", comprises short peptides with diverse properties including antimicrobial activity, lytic activity and the potentiation of bradykinin and cell signaling [24]. These peptides are considered to belong to the broader category of antimicrobial peptides (AMPs), an important component of innate immunity in many different organisms, due to their ability to inhibit the growth of pathogens including multidrug-resistant bacteria at MIC values as low as $1 \mu \mathrm{M}[18,19,25]$. Scorpion venom AMPs therefore provide a rich source of potential new antimicrobial compounds that could be used to address the increasing prevalence of pathogens resistant to conventional antibiotics. However, many scorpion AMPs also cause undesirable levels of hemolysis and cytotoxicity, so the use of natural peptides would cause unacceptable side effects. It may nevertheless be possible to exploit these peptides if peptide engineering can be used to balance potency with increased selectivity against pathogens [26].

Natural AMPs in scorpion venom are highly conserved (Figure 1) as shown by their phylogenetic clustering (Figure 2), and in some cases the difference between AMPs can be as little as one or two residues. Interestingly, such small differences in sequence often result in much larger differences in bioactivity. For example, UyCT1 from $U$. yaschenkoi [18] and Um3 from $U$. manicatus [20] differ at only one residue (S12N), but this substitution makes UyCT1 more potent that Um3 (Table 3). The degree of conservation among scorpion venom AMPs is such that some diverse species produce identical AMPs, e.g., StCT2 from S. tibetanus [27] is identical to Um3 from U. manicatus, and UyCT3 from the Australian scorpion $U$. yaschenkoi [18] is identical to OcyC1 from the Brazilian scorpion Opisthacanthus cayaporum [28]. UyCT3 differs from Um5 at two positions (L2F and S3K), and the nature of the substitutions increases the net positive charge on Um5, increasing its activity against all the bacteria we tested (Table 3). These natural substitutions led to our hypothesis that a rational engineering approach could be used to modify scorpion AMPs to increase their potency and specificity for microbial membranes, thereby reducing their hemolytic activity and cytotoxicity towards mammalian cells and thus improving their therapeutic index.

Here, we compared the bioactivity of natural and engineered scorpion AMPs to investigate their suitability as therapeutic leads. In order to preserve the secondary structure of the natural AMPs as far as possible, changes were only made in non-essential residues and their purpose was to increase the positive net charge (Table 2). The UyCT peptides showed low MIC values (1-15 $\mu \mathrm{M})$ against several human pathogens, including multidrug resistant bacteria, but they also caused mild hemolysis [19]. Rational engineering was most successful in the case of UyCT1, where the addition of a C-terminal oligo-lysine tail to generate engineered derivative D11 reduced the hemolytic activity to negligible levels $\left(\mathrm{HC}_{50}=1110 \mu \mathrm{M}\right)$ compared to the parental UyCT1 $\left(\mathrm{HC}_{50}=142.5 \mu \mathrm{M}\right)$. The increase in net positive charge and the bulky side chains made the peptide more potent and also more selective towards bacteria (Table 3).

Another potential way to improve selective antimicrobial activity is to modulate the charge distribution of amphipathic helices, i.e., increase the hydrophobicity of the hydrophobic face and/or the hydrophilicity of the hydrophilic face [29]. We increased the net positive charge of UyCT1 by adding lysine residues either at the C-terminus or distributed along the parent sequence (Table 2). As stated above, the engineered peptide D11 (C-terminal oligo-lysine tail) had a much lower MIC than the parental peptide UyCT1 $(\sim 1 \mu \mathrm{M}$ compared to $\sim 4 \mu \mathrm{M})$ against all seven bacteria tested (Table 3), probably reflecting the formation of a more effective membrane-transducing domain [30]. In contrast, D12 (based on UyCT1 but with distributed lysine residues) was totally inactive (data not shown). Similar results were observed with UyCT1 when we replaced the negatively charged glutamic acid residue with lysine (E8K) to generate the D4 derivative. The D4 peptide was less potent than UyCT1 (Table 3) but also showed no hemolytic activity (Table 3). Similarly, D5 was derived from UyCT1 by replacing tryptophan with leucine (W6L) and it showed only $~ 25 \%$ of the activity of the parental AMP (Table 3), probably because the presence of the large tryptophan side chain enhances the membrane 
purterbation [31]. These findings suggest that an increase in the net positive charge can increase the potency of AMPs but only if the charge is concentrated at the end of the peptide and not distributed throughout the sequence.

The engineered peptides D5, D10 and D11 showed a significant loss of hemolytic activity compared to their parent sequences (Table 3), substantially increasing the corresponding therapeutic index, especially in the case of D11 (Table 4). D5 is a derivative of UyCT1 with W7L and N12K substitutions, and D10 is a derivative of Uy234 with the addition of four scattered lysine residues (Table 2). The hemolytic activity of these engineered peptides was 100-fold lower than the parent peptides (Table 3). However, more sophisticated engineering approaches are required to reduce $\mathrm{HC}_{50}$ values. For example, the naturally occurring peptides UyCT3 and Um5 differ at two residues (positions 2 and 3) but their $\mathrm{HC}_{50}$ values are almost identical $(\sim 60 \mu \mathrm{M})$, whereas UyCT1 and Um3 differ only at position 12 and the $\mathrm{HC}_{50}$ values are 142.5 and $126.2 \mu \mathrm{M}$, respectively. The hemolytic effect of AMPs may depend more on the stereochemistry of the residues than the nature of the substitution [16], so L-to-D replacements may offer a better strategy to reduce the hemolytic activity of scorpion AMPs [32].

Table 4. Therapeutic indices (TI) of the native and engineered scorpion AMPs. The indices were calculated based on $\mathrm{HC}_{50}$ values.

\begin{tabular}{ccccccc}
\hline AMP & M. luteus & E. coli & S. aureus & L. grayi & L. fleischmannii & L. monocytogenes \\
\hline UyCT1 & 142.50 & 35.62 & - & 35.62 & 35.62 & 35.62 \\
\hline UyCT3 & 14.53 & 7.26 & - & 7.26 & 14.53 & 14.53 \\
\hline UyCT5 & 5.14 & 1.37 & 2.57 & 2.57 & 2.57 & 5.14 \\
\hline Uy17 & 9.22 & - & 4.61 & - & - & 9.22 \\
\hline Uy192 & 10.37 & 10.37 & 10.37 & 10.37 & 38.90 & 19.45 \\
\hline Uy234 & 52.25 & - & - & 26.12 & - & 52.25 \\
\hline Um2 & 32.25 & - & - & - & - & - \\
\hline Um3 & 63.10 & 8.41 & 8.41 & 31.55 & 31.55 & - \\
\hline Um4 & - & - & - & - & 29.77 \\
\hline Um5 & 29.62 & 3.95 & - & 29.62 & 11.99 & 11.99 \\
\hline D1 & 11.99 & 5.99 & - & 5.99 & 1.63 & 1.63 \\
\hline D2 & 6.12 & - & 3.06 & - & - & - \\
\hline D4 & - & - & - & - & 109.06 & 109.06 \\
\hline D5 & 204.50 & 109.06 & - & 204.50 & 57.53 & 57.53 \\
\hline D10 & 6904 & 215.75 & - & 215.75 & 1110 & 555 \\
\hline D11 & 4440 & 277.5 & - & - & - & -62 \\
\hline
\end{tabular}

UyCT3 and D1 differed at two positions (L2F and S3G) but behaved similarly in terms of antibacterial and hemolytic activities (Table 3), possibly because both leucine and phenylalanine are lipophilic with neutral nonpolar side-chains. Similarly, replacing serine with glycine has only a limited effect, probably because these residues have similar hydrophobicity. In contrast, Uy192 and D2 also differed at two positions (G11S and L13F) but the engineered version was more potent and the hemolytic activity was lower, even though the same pairs of residues were exchanged (Table 3), suggesting that the size of the side chains may have affected the conformation of the peptide in a favorable manner [19].

Although these peptides showed promising antibacterial activity, they were inactive towards phytopathogenic fungi. Similarly, opisin from Opistophthalmus glabrifrons was able to inhibit a range of bacteria such as S. aureus, M. luteus, Bacillus megaterium, B. thuringiensis and Nocardia coralline, 
but showed only a weak activity against Candida tropicalis [33]. One possible reason for such specificity towards bacteria is the effective electrostatic interaction of scorpion AMPs with the bacterial membrane - as a determinant factor for the bacterial viability — whereas acting against fungi via targeting cell wall components and/or intracellular molecules needs more complex interactions, which might be achieved through the synergism between different peptides [34,35].

In summary, our rational engineering approach yielded a number of derivative peptides with therapeutic indices better than the natural parental peptides. In particular, peptides D4, D5, D10 and D11 showed more potent antimicrobial activity and lower hemolytic and cytotoxic activity. D10 and D11 showed the highest activity against diverse bacteria and would be suitable as leads for the development of a new generation of antimicrobial products to address the prevalent threat of multidrug-resistant bacterial pathogens.

\section{Materials and Methods}

\subsection{Natural and Engineered AMPS}

DNA sequences corresponding to the UyCT peptides were isolated from a cDNA library constructed from $U$. yaschenkoi telson total RNA [18]. The Uy17, Uy192 and Uy234 sequences were found in the transcriptome of the $U$. yaschenkoi venom gland [17]. The $U$. manicatus Um1, Um2, Um3, Um4 and Um5 sequences were previously described [20]. Engineered AMPs (D1-D12) were prepared based on the inherent structural characteristics of the sequences of UyCTx, Uy192 and Uy234. After selecting the conserved residues, four major structural determinants were considered: hydrophobicity, net charge, amphipathicity and helical conformation. All of the engineered AMPs were C-terminally amidated. The amino acid sequences, molecular masses and structural parameters for the engineered and natural AMPs described herein are summarized in Table 1. We investigated 16 peptides in this study, and they were chemically synthetized by CASLO (Kongens Lyngby, Denmark).

\subsection{Antimicrobial Activity}

The minimal inhibitory concentration (MIC) of each AMPs was determined against the Gram-positive bacteria Listeria monocytogenes (DSM20600), L. grayi (DSM20601), L. fleischmannii (DSM24998), Staphylococcus aureus (DSM2569) and Micrococcus luteus (DSM20030), and the Gram-negative species Escherichia coli (D31) and Pseudomonas aeruginosa (DSM50071). The scorpion peptides were prepared at concentrations of 0.015-250 $\mu \mathrm{M}$. The assays were carried out in 384-well plates (Greiner Bio One, Frickenhausen, Germany) using Brain Heart Infusion Broth (BHIB) medium for Listeria spp., Tryptic Soy Broth (TSB) for S. aureus, and lysogeny broth (LB) for the others. The bacteria were cultivated overnight at either $37^{\circ} \mathrm{C}$ (Listeria spp., S. aureus, E. coli and P. aeruginosa) or $30^{\circ} \mathrm{C}$ (M. luteus) and subcultured in fresh media before the growth inhibition assays. Growth inhibition was measured as previously described [8]. Each assay was carried out at least three times and the MIC was recorded as the AMP concentration at which bacterial growth was totally inhibited (Figure S1).

\subsection{Antifungal Assays}

Antifungal activity was tested using Fusarium culmorum and F. graminearum strain 8/1 [34]. The fungi were cultured in the dark on Nirenberg Synthetic Nutrient Agar plates at $18{ }^{\circ} \mathrm{C}$ for $1-2$ weeks and the harvested spores were incubated in tap water supplemented with 2-200 $\mu \mathrm{M}$ of each AMP at room temperature for $24 \mathrm{~h}$ in the dark [8,35]. The antifungal MIC was recorded as the AMP concentration at which spore germination was totally inhibited.

\subsection{Hemolytic Activity}

The hemolytic activity of each AMP was determined using pig erythrocytes [19]. Serial dilutions (6.25-100 $\mu \mathrm{M}$ ) of each AMP were prepared, and after incubation for $1 \mathrm{~h}$ at $37{ }^{\circ} \mathrm{C}$ the cells were centrifuged and the absorbance of the supernatant was measured at $570 \mathrm{~nm}$ using an Eon Microplate 
Spectrophotometer (BioTek Instruments, Winooski, VT, USA). Three independent experiments were carried out for each concentration in triplicate. PBS and 10\% Triton X-100 were used as negative and positive controls, respectively. The percentage hemolysis was calculated using the formula $100\left(\left(A_{\text {peptide }}-A_{P B S}\right) /\left(A_{\text {triton }}-A_{P B S}\right)\right)$. The AMP concentration causing $50 \%$ hemolysis $\left(\mathrm{HC}_{50}\right)$ of the pig erythrocytes was determined by non-linear regression with the data fitted to the logistical sigmoidal equation, using GraphPad Prism v5.0 (GraphPad Software, San Diego, CA, USA) (Figure S2).

\subsection{Cytotoxic Activity}

Cytotoxicity was evaluated using the baby hamster kidney cell line (BHK-21) included in F2 $\mathrm{H}^{\circledR}$-Kit Basic (Chromotek, Planegg-Martinsried, Germany). The BHK-21 cells were grown in 25- $\mathrm{cm}^{2}$ cell culture flasks (Greiner Bio One, Frickenhausen, Germany) containing Dulbecco's Modified Eagle's Medium (DMEM) supplemented with $4.5 \mathrm{~g} / \mathrm{L}$ glucose, $110 \mathrm{mg} / \mathrm{L}$ sodium pyruvate and L-glutamine, and $10 \%$ fetal bovine serum (FBS), and were maintained in an NU-5810 incubator (ibs tecnomara, Fernwald, Germany) at $37^{\circ} \mathrm{C}$ with a $5 \% \mathrm{CO}_{2}$ atmosphere. The cells were subcultured at $\sim 90 \%$ confluence by detaching with $0.25 \%$ trypsin and $0.03 \%$ EDTA (Sigma-Aldrich, St Louis, MO, USA). The AMPs were dissolved in water and diluted to final concentrations of $0.1,1,10$ and $100 \mu \mathrm{M}$ in DMEM.

BHK-21 cells were prepared and tested as previously described [36,37]. Confluent cells were detached, counted and seeded at a concentration of $8.5 \times 10^{4}$ cell/mL in a 96-well culture plate (Greiner Bio One-Cell Star) $48 \mathrm{~h}$ before each experiment. The cells were rinsed with $100 \mu \mathrm{L}$ PBS before adding $100 \mu \mathrm{L}$ of the AMP solution and incubating for $2 \mathrm{~h}$ at $37^{\circ} \mathrm{C}$. The AMP solution was then removed and the cells were rinsed again with PBS before staining with $10 \% \mathrm{v} / \mathrm{v}$ alamarBlue ${ }^{\mathrm{TM}}$ Dye (Thermo Fisher Scientific, Schwerte, Germany) in DMEM for $1 \mathrm{~h}$. The fluorescence of the metabolized alamarBlue ${ }^{\mathrm{TM}}$ Dye was measured in an Eon microplate reader using excitation and emission filters of 528 and $590 \mathrm{~nm}$, respectively. DMEM and cells exposed to DMEM without AMPs were included as a blank reference and negative control, respectively. Four independent experiments were carried out for each AMP concentration in triplicate. To assess the percentage of viable cells compared to the control, the data were analyzed with GraphPad Prism v5.0 software using non-linear regression to fit the curve (Figure S2). The $\mathrm{EC}_{50}$ was reported as the AMP concentration that reduces cell viability by $50 \%$.

\subsection{Phylogenetic Analysis}

The amino acid sequences were aligned using Clustal Omega [38]. To assess the evolutionary distance between scorpion AMPs, a phylogenetic tree was built using ClustalW2 Phylogeny on the EMBL-EBI platform with the Nexus UPGMA model. All natural scorpion AMPs with observed activities were included in the tree.

Supplementary Materials: The following are available online at www.mdpi.com/2072-6651/9/1/22/s1, Figure S1: Growth inhibition assays, Figure S2: Cytotoxicity and Hemolysis graphs.

Acknowledgments: The authors acknowledge generous funding by the Hessen State Ministry of Higher Education, Research and the Arts (HMWK) via the "LOEWE Center for Insect Biotechnology and Bioresources". We thank Richard M. Twyman for editing the manuscript.

Author Contributions: Karen Luna-Ramirez conceived and designed the experiments. Karen Luna-Ramirez and Miray Tonk performed the experiments. Karen Luna-Ramirez and Miray Tonk analyzed the data. Andreas Vilcinskas contributed reagents/materials/analysis tools. Karen Luna-Ramirez, Mohammad Rahnamaeian and Miray Tonk wrote the paper.

Conflicts of Interest: The authors declare that they have no conflict of interest.

\section{References}

1. Wiesner, J.; Vilcinskas, A. Antimicrobial peptides: The ancient arm of the human immune system. Virulence 2010, 1, 440-464. [CrossRef] [PubMed]

2. Mylonakis, E.; Podsiadlowski, L.; Muhammed, M.; Vilcinskas, A. Diversity, evolution and medical applications of insect antimicrobial peptides. Phil. Trans. R. Soc. B 2016, 371, 20150290. [CrossRef] [PubMed] 
3. Bolouri Moghaddam, M.R.; Tonk, M.; Schreiber, C.; Salzig, D.; Czermak, P.; Vilcinskas, A.; Rahnamaeian, M. The potential of the Galleria mellonella innate immune system is maximized by the co-presentation of diverse antimicrobial peptides. Biol. Chem. 2016, 397, 939-945. [CrossRef] [PubMed]

4. Bolouri Moghaddam, M.R.; Vilcinskas, A.; Rahnamaeian, M. Cooperative interaction of antimicrobial peptides with the interrelated immune pathways in plants. Mol. Plant Pathol 2016, 17, 464-471. [CrossRef] [PubMed]

5. Vilcinskas, A. Evolutionary plasticity of insect immunity. J. Insect Physiol. 2013, 59, 123-129. [CrossRef] [PubMed]

6. Al Souhail, Q.; Hiromasa, Y.; Rahnamaeian, M.; Giraldo, M.C.; Takahashi, D.; Valent, B.; Vilcinskas, A.; Kanost, M.R. Characterization and regulation of expression of an antifungal peptide from hemolymph of an insect, Manduca sexta. Dev. Comp. Immunol. 2016, 61, 258-268. [CrossRef] [PubMed]

7. Tonk, M.; Knorr, E.; Cabezas-Cruz, A.; Valdes, J.J.; Kollewe, C.; Vilcinskas, A. Tribolium castaneum defensins are primarily active against gram-positive bacteria. J. Invertebr. Pathol. 2015, 132, 208-215. [CrossRef] [PubMed]

8. Tonk, M.; Cabezas-Cruz, A.; Valdes, J.J.; Rego, R.O.; Chrudimska, T.; Strnad, M.; Sima, R.; Bell-Sakyi, L.; Franta, Z.; Vilcinskas, A.; et al. Defensins from the tick Ixodes scapularis are effective against phytopathogenic fungi and the human bacterial pathogen listeria grayi. Parasit. Vectors 2014, 7, 554-561. [CrossRef] [PubMed]

9. Tonk, M.; Cabezas-Cruz, A.; Valdes, J.J.; Rego, R.O.; Grubhoffer, L.; Estrada-Pena, A.; Vilcinskas, A.; Kotsyfakis, M.; Rahnamaeian, M. Ixodes ricinus defensins attack distantly-related pathogens. Dev. Comp. Immunol. 2015, 53, 358-365. [CrossRef] [PubMed]

10. Harrison, P.L.; Abdel-Rahman, M.A.; Miller, K.; Strong, P.N. Antimicrobial peptides from scorpion venoms. Toxicon 2014, 88, 115-137. [CrossRef] [PubMed]

11. Abdel-Rahman, M.A.; Quintero-Hernandez, V.; Possani, L.D. Venom proteomic and venomous glands transcriptomic analysis of the egyptian scorpion Scorpio maurus palmatus (arachnida: Scorpionidae). Toxicon 2013, 74, 193-207. [CrossRef] [PubMed]

12. Du, Q.; Hou, X.; Wang, L.; Zhang, Y.; Xi, X.; Wang, H.; Zhou, M.; Duan, J.; Wei, M.; Chen, T.; et al. AaeAP1 and AaeAP2 : Novel antimicrobial peptides from the venom of the scorpion, Androctonus aeneas: Structural characterisation, molecular cloning of biosynthetic precursor-encoding cdnas and engineering of analogues with enhanced antimicrobial and anticancer activities. Toxins (Basel) 2015, 7, 219-237. [PubMed]

13. Giangaspero, A.; Sandri, L.; Tossi, A. Amphipathic $\alpha$ helical antimicrobial peptides. Eur. J. Biochem. 2001, 268, 5589-5600. [CrossRef] [PubMed]

14. Zasloff, M. Preface. Philos. Trans. R. Soc. B 2016, 371. [CrossRef] [PubMed]

15. Park, Y.; Kim, H.N.; Park, S.N.; Jang, S.H.; Choi, C.H.; Lim, H.T.; Hahm, K.S. Design of novel analogues with potent antibiotic activity based on the antimicrobial peptide, HP(2-9)-ME(1-12). Biotechnol. Lett. 2004, 26, 493-498. [CrossRef] [PubMed]

16. Rahnamaeian, M.; Vilcinskas, A. Short antimicrobial peptides as cosmetic ingredients to deter dermatological pathogens. Appl. Microbiol. Biotechnol. 2015, 99, 8847-8855. [CrossRef] [PubMed]

17. Luna-Ramirez, K.; Quintero-Hernandez, V.; Juarez-Gonzalez, V.R.; Possani, L.D. Whole transcriptome of the venom gland from Urodacus yaschenkoi scorpion. PLoS ONE 2015, 10, e0127883. [CrossRef] [PubMed]

18. Luna-Ramírez, K.; Quintero-Hernández, V.; Vargas-Jaimes, L.; Batista, C.V.F.; Winkel, K.D.; Possani, L.D. Characterization of the venom from the australian scorpion Urodacus yaschenkoi: Molecular mass analysis of components, cdna sequences and peptides with antimicrobial activity. Toxicon 2013, 63, 44-54. [CrossRef] [PubMed]

19. Luna-Ramírez, K.; Sani, M.-A.; Silva-Sanchez, J.; Jiménez-Vargas, J.M.; Reyna-Flores, F.; Winkel, K.D.; Wright, C.E.; Possani, L.D.; Separovic, F. Membrane interactions and biological activity of antimicrobial peptides from Australian scorpion. BBA-Biomembranes 2014, 1838, 2140-2148. [CrossRef] [PubMed]

20. Sunagar, K.; Undheim, E.A.B.; Chan, A.H.C.; Koludarov, I.; Muñoz-Gómez, S.A.; Antunes, A.; Fry, B.G. Evolution stings: The origin and diversification of scorpion toxin peptide scaffolds. Toxins 2013, 5, 2456-2487. [CrossRef] [PubMed]

21. Quintero-Hernández, V.; Ramírez-Carreto, S.; Romero-Gutiérrez, M.T.; Valdez-Velázquez, L.L.; Becerril, B.; Possani, L.D.; Ortiz, E. Transcriptome analysis of scorpion species belonging to the Vaejovis genus. PLoS ONE 2015, 10, e0117188. [CrossRef] [PubMed] 
22. Luan, N.; Shen, W.; Liu, J.; Wen, B.; Lin, Z.; Yang, S.; Lai, R.; Liu, S.; Rong, M. A combinational strategy upon RNA sequencing and peptidomics unravels a set of novel toxin peptides in scorpion Mesobuthus martensii. Toxins (Basel) 2016, 8, 286-299. [CrossRef] [PubMed]

23. Ali, S.A.; Alam, M.; Abbasi, A.; Undheim, E.A.; Fry, B.G.; Kalbacher, H.; Voelter, W. Structure-activity relationship of chlorotoxin-like peptides. Toxins (Basel) 2016, 8, 36-53. [CrossRef] [PubMed]

24. Guo, X.; Ma, C.; Du, Q.; Wei, R.; Wang, L.; Zhou, M.; Chen, T.; Shaw, C. Two peptides, TsAP-1 and TsAP-2, from the venom of the brazilian yellow scorpion, Tityus serrulatus: Evaluation of their antimicrobial and anticancer activities. Biochimie 2013, 95, 1784-1794. [CrossRef] [PubMed]

25. Almaaytah, A.; Albalas, Q. Scorpion venom peptides with no disulfide bridges: A review. Peptides 2014, 51, 35-45. [CrossRef] [PubMed]

26. Deslouches, B.; Steckbeck, J.D.; Craigo, J.K.; Doi, Y.; Mietzner, T.A.; Montelaro, R.C. Rational design of engineered cationic antimicrobial peptides consisting exclusively of arginine and tryptophan, and their activity against multidrug-resistant pathogens. Antimicrob Agents Ch. 2013, 57, 2511-2521. [CrossRef] [PubMed]

27. Cao, L.; Li, Z.; Zhang, R.; Wu, Y.; Li, W.; Cao, Z. Stct2, a new antibacterial peptide characterized from the venom of the scorpion Scorpiops tibetanus. Peptides 2012, 36, 213-220. [CrossRef]

28. Silva, E.C.; Camargos, T.S.; Maranhao, A.Q.; Silva-Pereira, I.; Silva, L.P.; Possani, L.D.; Schwartz, E.F. Cloning and characterization of cDNA sequences encoding for new venom peptides of the brazilian scorpion Opisthacanthus cayaporum. Toxicon 2009, 54, 252-261. [CrossRef] [PubMed]

29. Uggerhoj, L.E.; Poulsen, T.J.; Munk, J.K.; Fredborg, M.; Sondergaard, T.E.; Frimodt-Moller, N.; Hansen, P.R.; Wimmer, R. Rational design of alpha-helical antimicrobial peptides: Do's and don'ts. Chembiochem 2015, 16, 242-253. [CrossRef] [PubMed]

30. Sakai, N.; Matile, S. Anion-mediated transfer of polyarginine across liquid and bilayer membranes. J. Am. Chem. Soc. 2003, 125, 14348-14356. [CrossRef] [PubMed]

31. Chan, D.I.; Prenner, E.J.; Vogel, H.J. Tryptophan- and arginine-rich antimicrobial peptides: Structures and mechanisms of action. Biochim. Biophys. Acta 2006, 1758, 1184-1202. [CrossRef] [PubMed]

32. Albada, H.B.; Prochnow, P.; Bobersky, S.; Langklotz, S.; Bandow, J.E.; Metzler-Nolte, N. Short antibacterial peptides with significantly reduced hemolytic activity can be identified by a systematic L-to-D exchange scan of their amino acid residues. ACS Comb. Sci. 2013, 15, 585-592. [CrossRef] [PubMed]

33. Bao, A.; Zhong, J.; Zeng, X.C.; Nie, Y.; Zhang, L.; Peng, Z.F. A novel cysteine-free venom peptide with strong antimicrobial activity against antibiotics-resistant pathogens from the scorpion Opistophthalmus glabrifrons. J. Pept. Sci. 2015, 21, 758-764. [CrossRef] [PubMed]

34. Rahnamaeian, M.; Cytrynska, M.; Zdybicka-Barabas, A.; Vilcinskas, A. The functional interaction between abaecin and pore-forming peptides indicates a general mechanism of antibacterial potentiation. Peptides 2016, 78, 17-23. [CrossRef] [PubMed]

35. Rahnamaeian, M.; Langen, G.; Imani, J.; Khalifa, W.; Altincicek, B.; von Wettstein, D.; Kogel, K.H.; Vilcinskas, A. Insect peptide metchnikowin confers on barley a selective capacity for resistance to fungal ascomycetes pathogens. J. Exp. Bot. 2009, 60, 4105-4114. [CrossRef] [PubMed]

36. Ponce, D.; Brinkman, D.L.; Luna-Ramirez, K.; Wright, C.E.; Dorantes-Aranda, J.J. Comparative study of the toxic effects of Chrysaora quinquecirrha (cnidaria: Scyphozoa) and Chironex fleckeri (cnidaria: Cubozoa) venoms using cell-based assays. Toxicon 2015, 106, 57-67. [CrossRef] [PubMed]

37. Dorantes-Aranda, J.J.; Waite, T.D.; Godrant, A.; Rose, A.L.; Tovar, C.D.; Woods, G.M.; Hallegraeff, G.M. Novel application of a fish gill cell line assay to assess ichthyotoxicity of harmful marine microalgae. Harmful Algae 2011, 10, 366-373. [CrossRef]

38. Sievers, F.; Wilm, A.; Dineen, D.; Gibson, T.J.; Karplus, K.; Li, W.; Lopez, R.; McWilliam, H.; Remmert, M.; Söding, J.; et al. Fast, Scalable generation of high-quality protein multiple sequence alignments using Clustal omega. Mol. Syst. Biol. 2011, 7, 539. [CrossRef] [PubMed]

(C) 2017 by the authors; licensee MDPI, Basel, Switzerland. This article is an open access article distributed under the terms and conditions of the Creative Commons Attribution (CC-BY) license (http:/ / creativecommons.org/licenses/by/4.0/). 